\title{
HISTÓRIA, ALEGORIA E SURREALISMO NA FILOSOFIA DE WALTER BENJAMIN
}

\author{
Rubens José da Rocha ${ }^{1}$
}

\begin{abstract}
RESUMO
Com o propósito de elucidar nexos que ligam o conceito de alegoria ao método de escrita das Passagens de Paris, farei uma breve exposição da crítica de Benjamin à historiografia romântica e positivista, comparando sua proposta de um pensamento por imagens à estética surrealista de Breton.
\end{abstract}

Palavras-chave: Alegoria. Forma. História. Ideia. Imagem. Montagem.

\begin{abstract}
In order to elucidate connections linking the concept of allegory to the method of writing the work Passages de Paris, I will make a brief presentation of the critique of Benjamin on romantic and positivist historiography, comparing his proposal of a thought by images to the surrealist aesthetic of Breton.
\end{abstract}

Keywords: Allegory. Form. History. Idea. Image. Montage.

\section{a) História: crítica aos modelos romântico e positivista}

A rápida mudança nas formas de estruturação do saber, ocorrida no século XIX, reforçaria a tese de uma história que poderia ser captada de maneira objetiva por modelos discursivos depurados da linguagem oral. Assim, o manejo de dados documentais e estatísticos, predominante no ambiente acadêmico alemão na década de 1920, faria de exigências como as de imparcialidade e objetividade, comuns às ciências experimentais, critério de legitimidade do discurso entre historiadores positivistas. ${ }^{2}$ Como se sabe, essa situação instigou Benjamina investigar as motivações ideológicas envoltas no conceito de progresso. O filósofo deixaria claro, em diversos ensaios, sua posição quanto ao fundamento do relato histórico, como no escrito sobre a função do narrador em Leskov: "A experiência que passa de pessoa a pessoa é a fonte a que recorreram todos os narradores, e, entre as narrativas escritas, as melhores são as que menos se distinguem das histórias

1 Doutorando pelo Programa de Pós-Graduação em Filosofia da Universidade Federal de São Carlos (UFSCar).E-mail: ens_rubens@yahoo.com.br

2 A hipótese positivista da sucessão homogênea dos fatos e sua correspondência com a ordem do discurso pode ser lida como revisão da conhecida distinção de Aristóteles entre poesia como narração de acontecimentos possíveis e história como narração de fatos que realmente aconteceram: "A diferença [entre historiador e poeta] está em que um narra acontecimentos e o outro, fatos quais podiam acontecer", ARISTÓTELES, Poética, in A Poética Clássica, IX, p. 28. 
orais contadas pelos inúmeros narradores anônimos". 3 Assim, antes de assumir uma atitude teórica definida, o historiador não dispõe de outro modelo para avaliar o teor objetivo do que é relatado senão sua própria experiência e a experiência da comunidade, não implicando nenhum ganho na compreensão do passado o uso de modelos discursivos supostamente impessoais. ${ }^{4}$

A concepção do relato histórico como transmissão da experiência individual e ao mesmo tempo coletiva já se encontrava na tese sobre a Origem do Drama Barroco Alemão. Logo na abertura, Benjamin elogiava o tratado medieval como modelo que, segundo ele, escapava ao domínio tirânico do more geometrico, permitindo ao pesquisador imergir naquilo que, de direito, aparecia como seu território autêntico: a linguagem e a história. Imunes ao dogma científico, os tratadistas não se solidarizavam nem com a fama das doutrinas filosóficas, nem com os métodos demonstrativos da matemática, recorrendo a "um único elemento de intenção didática, mais voltada para a educação que para o ensinamento: a citação autorizada". ${ }^{5}$ À medida que se distanciavam da pretensão de legislar sobre o conhecimento, os tratados abriam a possibilidade de desvio do olhar, facilitando o contato com os vários estratos de significação do objeto. À semelhança de um mosaico, a linguagem assumia a função de justapor elementos isolados e heterogêneos, na tentativa sempre renovada de captar os pormenores sensíveis, forçando "o pensamento a começar sempre de novo e voltar sempre, minuciosamente, às próprias coisas". ${ }^{6}$

Esse primeiro passo teórico realçará a proposta de uma interpretação filosófica do drama barroco, afastando o filósofo de abordagens histórico-culturais, históricoliterárias ou biográficas correntes no séc. XIX. Segundo Benjamin, o mau uso destes métodos de interpretação será uma das principais causas do rebaixamento do drama barroco por críticos e historiadores românticos. Ao conceber o símbolo como forma mais acabada de expressão da experiência humana, historiadores românticos

\footnotetext{
3 BENJAMIN, W. O Narrador (1936), in Magia e Técnica, Arte e Política, p.198.

4 "Na substituição da antiga forma narrativa pela informação, e da informação pela sensação refletese a crescente atrofia da experiência. Todas essas formas, por sua vez, se distinguem da narração, que é uma das mais antigas formas de comunicação. Esta não tem a pretensão de transmitir um acontecimento, pura e simplesmente (como a informação o faz); integra-o à vida do narrador, para passá-lo aos ouvintes como experiência. Nela ficam impressas as marcas do narrador como os vestígios das mãos do oleiro no vaso de argila". BENJAMIN, W. Charles Baudelaire, Um Lírico no Auge do Capitalismo, p.106.

5 BENJAMIN, W. Origem do Drama Barroco Alemão, p.50.

${ }^{6}$ BENJAMIN, W. Origem do Drama Barroco Alemão, p.50.
} 
interpretaram a alegoria como má realização do modelo clássico de tragédia, ou seja, como incapacidade artística para elevar os elementos formais do drama à categoria do belo. Avançando na teoria de Fichte e Schiller, Novalis e Schlegel concebiam a unidade da obra como produto da atividade sintética da imaginação, ou seja, como desdobramento infinito de uma reflexão que elabora a linguagem de modo a dispô-la em relação de consonância com a ideia de um todo da obra: "na exposição de suas relações com todas as demais obras e, finalmente, com a ideia da arte". ${ }^{7}$ A reflexão cumpria, assim, a tarefa de representar a multiplicidade sensível em conformidade com a consciência de si, a unidade sintética da a percepção, como já acontecia na filosofia de Kant. O problema dessa reflexão infinita, teorizada por Schlegel como autorreflexão dos elementos de composição (significantes, símbolos, figuras),é que ela não poderá referir-se a nada exterior à sua ação, a saber, à ação reflexiva do pensamento,exigindo sempre uma unidade sintética como força capaz de impulsionar a linguagem na direção da ideia do todo.

Quando confrontado com o segundo, o terceiro grau de reflexão significa algo fundamentalmente novo. O segundo, o pensar do pensar, é a forma originária, a forma canônica da reflexão; como tal Fichte também 0 reconheceu na "forma da forma como seu conteúdo". A partir do terceiro e dos consecutivos graus mais elevados da reflexão ocorre uma decomposição dessa forma originária, que se manifesta numa ambiguidade peculiar. $^{8}$

Todo esforço de Benjamim na tese sobre o drama barroco será desconstruir essa exigência de remissão da linguagem à unidade e à totalidade. Em contraste com a teoria romântica do símbolo e do belo, a alegoria terá como princípio a produção de ambivalências provocadas não pela reflexão, mas pela tensão entre a vida pulsante do intérprete e a materialidade dos elementos que compõem as obras. Arrancados do contexto usual para figurar como fragmentos descontínuos, seus elementos serão bruscamente subtraídos à função orgânica de origem, passando a figurar como significantes vazios que abrem a possibilidade de múltiplas interpretações: "Enquanto o conceito emerge da espontaneidade do entendimento, as ideias se oferecem à contemplação". 9 A alegoria privilegiará, portanto, a livre

\footnotetext{
7 BENJAMIN, W. O Conceito de Crítica de Arte no Romantismo Alemão, p.83

8 BENJAMIN, W. O Conceito de Crítica de Arte no Romantismo Alemão, p.38.

9 BENJAMIN, W. Origem do Drama Barroco Alemão, p. 52.
} 
associação do sentido, no esforço de revelar a incompletude e o despedaçamento de realidades ainda não superadas, como sugere Rouanet: "O alegorista arranca 0 objeto de seu contexto. Mata-o. E o obriga a significar. Esvaziado de todo brilho próprio, incapaz de irradiar qualquer sentido, ele está pronto para funcionar como alegoria". ${ }^{10}$ Sua tarefa será exibir, nos fragmentos que constituem as obra, a face deformada da história, como denúncia da barbárie, da catástrofe e do sofrimento humanos. Justapostos de maneira pouco habitual, esses fragmentos cumprem 0 papel de estimular a sensibilidade do leitor, impregnando-o com uma sensação de melancolia que, ao poucos, o desperta para o exercício de interpretar. Desse modo, o procedimento alegórico descortina o sentido histórico dos fragmentos sem recorrer a um modelo discursivo supostamente capaz de captar o todo objetivo. O sentido não poderá aparecer nunca como autoevidente, mas apenas à maneira de um acaso objetivo que, ao conservar latente o nexo entre o fato e a razão, impulsiona a força sugestiva dos fragmentos para o intérprete. A partir daí, Benjamin estará a um passo de caracterizar a alegoria como forma de apresentação estética de monumentos históricos que não poderão aparecer senão sob o estado de ruínas.

\section{b) Imagens de sonho e imagens dialéticas}

Uma das propostas mais expressivas das teses sobre o conceito de história, escritas na década de 1930 para preceder a Obra das Passagens, era o deslocamento do modelo científico, incorporado ao método de exposição do relato histórico, para as formas de transmissão oral. Ao mesmo tempo em que refletiam a necessidade de ruptura com o modelo historiográfico positivista, as teses de Benjamin assumiam também a tarefa de reformular o materialismo histórico vulgarizado pelos intelectuais do partido comunista. ${ }^{11}$ No limite, acrítica à noção de progresso levaria à adoção da alegoria como método de captura das imagens históricas na Obra das Passagens. Esta obra inacabada é o esboço de um projeto de longos anos, cujo objetivo consistia na reconstituição da história de Paris do séc. XIX por meio da justaposição de imagens e citações. Sem desmerecer ou desqualificar o passado, o procedimento alegórico comprometia-se a incitar no leitor a interpretação do ocorrido, favorecendo a livre associação de sentido, no intuito de salvar a experiência social em sua verdade histórica. $O$ método de exposição seguia

\footnotetext{
${ }^{10}$ ROUANET, S.P. As Razões do lluminismo, p.40.

${ }^{11}$ BENJAMIN, W. Sobre o Conceito de História, in Magia e Técnica, Arte e Política.
} 
de perto as análises que Benjamin havia empreendido de expoentes literários da época, com especial atenção ao conceito de modernidade em jogo na lírica de Baudelaire: "Que Baudelaire se tenha colocado hostilmente perante o progresso foi a condição sine qua non para que pudesse dominar Paris em sua poesia". ${ }^{2}$

Pondo em prática seu projeto de conciliar experiência social e materialismo histórico, o filósofo considera as imagens a partir de dois grupos distintos, mas dialeticamente complementares. O primeiro grupo compreende as imagens de sonho definidas como projeção fantasmagórica do desejo sobre a vida desperta. $\mathrm{O}$ segundo são as imagens paralisadas, compreendidas como imagens de sonho que obstruem o acesso à verdade histórica por estarem sobrecarregadas com a presença "enfeitiçada" de um objeto ausente, que se fixa como imagem paralisada deixando vestígios sob a forma mercadoria. Com a atenção voltada para a fisionomia destas imagens nos fragmentos históricos, o filósofo espera não só revelar aspectos da experiência humana que foram destruídas ou camufladas pelas ideologias, mas também o modo como as ideologias dominantes representavam-se a si mesmas. As imagens de sonho seriam, portanto, a promessa de "presentificação" de um objeto ausente, capaz de reiterar a possibilidade de plena satisfação do desejo na vida desperta. Não encontrando satisfação no estado de vigília, o desejo projetaria no sonho a promessa de um novo horizonte de satisfação. De um lado, o desejo ver-se-ia forçado a amargar a falta do objeto desejado. De outro, ele seria impulsionado a buscar no sonho algo que preencheria esta ausência. Esta busca pelo prazer incondicionado levaria o sujeito a projetar as imagens de sonho nos objetos da vida desperta, constituindo toda a sorte de bens culturais que dão origem ao mito do progresso.

A novidade do produto adquire (como estimulante da demanda) um significado até então desconhecido; pela primeira vez, o sempre igual aparece de modo evidente na produção de massa. ${ }^{13}$

Assim, quando as imagens de sonho perdem sua eficácia simbólica, o desejo reincide na insatisfação, cristalizando-se no que Benjamin descreve como imagens paralisadas. Aprisionadas na materialidade dos objetos, ${ }^{14}$ as imagens paralisadas

\footnotetext{
${ }^{12}$ BENJAMIN, W. Charles Baudelaire, Um lírico no auge do capitalismo, p.174.

${ }^{13}$ BENJAMIN, W. Charles Baudelaire, Um lírico no auge do capitalismo, p.172.

${ }^{14}$ Sobre a relação entre fetiche e sociedade de consumo, reporto o leitor ao ensaio de Olgária Matos:

"A Cena Primitiva-Capitalismo e Fetiche em Walter Benjamin".
} 
aparecem como falseamento do trabalho, transfigurado na forma mercadoria. Por outro lado, apesar da multiplicidade de sua aparência e por conservar traços essenciais de objetos desde há muito visados pelo desejo recalcado, a forma mercadoria não poderá oferecer uma novidade efetiva. Em pleno estado de dormência, o sujeito não se apercebe de que sua busca por satisfação não the permite acesso à verdade das trocas sociais e, por conseguinte, à verdade do próprio desejo - que incessantemente se move na direção de uma nova satisfação.

Se a mercadoria tivesse uma alma - com a qual Marx, ocasionalmente faz graça -, esta seria a mais plena de empatia já encontrada no reino das almas, pois deveria procurar em cada um o comprador a cuja mão e a cuja morada se ajustar. Ora essa empatia é a própria essência da ebriedade à qual o flâneur se abandona na multidão. ${ }^{15}$

Enleada em devaneios hedonistas à sombra de imagens paralisadas, a massa sonhadora não poderá se dar conta de que suas projeções narcísicas são captadas pelo princípio da produção e do consumo. A história dessa relação malfadada do desejo com a natureza das trocas sociais é o que define as imagens dialéticas. Composição-síntese entre imagens paralisadas e imagens de sonho, as imagens dialéticas exprimem aquela camada de sentido inconsciente que escapa ao poder de formalização do conceito. Primeiro, são as imagens de sonho que, inconscientes e paralisadas, obstruem o acesso à verdade. Depois, a suspensão da paralisia que, através do procedimento alegórico, lança à luz do dia o objeto impossível do desejo. Ao descomprimir as imagens de sua forma paralisada, as imagens dialéticas superam a distinção lógico-causal entre diferentes contextos históricos, reconduzindo o intérprete a sua meta inicial: conceber a vida numa sociedade sem classes. As imagens dialéticas cumprem, portanto, a tarefa de favorecer a restituição do vigor original do desejo no alvorecer da consciência histórica.

A utilização dos elementos do sonho no despertar é o caso exemplar do pensamento dialético. Por isso, o pensamento dialético é o órgão do despertar histórico. Cada época sonha não apenas a próxima, mas ao sonhar, esforça-se em despertar. Traz em si mesma seu próprio fim e o desenvolve - como Hegel já o reconheceu - com astúcia. Com o abalo da

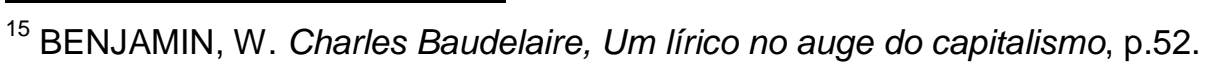


economia de mercado, começamos a reconhecer os monumentos da burguesia como ruínas antes mesmo de seu desmoronamento. ${ }^{16}$

Atento ao contorno das imagens, o intérprete alegorista acelera o poder de dissolução da paralisia, abrindo acesso à compreensão do sentido histórico que, ao atualizar a experiência coletiva, poderá desencadear a ação revolucionária.

\section{c) Benjamin e o surrealismo}

Sobre a Obra das Passagens, Adorno dizia que "sem vacilar, [Benjamin] assumia seu princípio fundamental de que a menor célula de realidade contemplada equivalia ao resto do mundo todo". ${ }^{17}$ É possível traçar, a partir desta concepção, um ponto de convergência entre Benjamin e Breton. Desde as incursões oníricas no cenário histórico alemão em Rua de Mão Única (1927) e o ensaio de 1929 dedicado ao movimento, a dívida de Benjamin com o surrealismo é patente. Na Obra das Passagens, a plurivocidade imagética e a promoção do acaso objetivo como via de acesso ao maravilhoso são algumas características que os aproximam. Com o Primeiro Manifesto Surrealista, Breton já se afastava da noção de analogia centrada no símbolo, por esta circunscrever a experiência estética em torno às prerrogativas do sujeito da representação. Apesar desse distanciamento comum, ambos os autores mantêm relações estreitas com a estética romântica - principalmente quanto ao papel da imaginação como faculdade central, não apenas para a percepção estética, mas também para a conduta ética e moral.

Apontando para os limites da filosofia da representação, Benjamin e Breton procuram na psicanálise arsenal teórico para valorizar a experiência do sonho como meio de superação de categorias estanques do sujeito. Para um e para outro, o fluxo supostamente irracional das imagens oníricas respeita uma lógica autônoma, arraigada à estrutura desejante do sujeito. Em contraste com a linearidade dos fenômenos aprisionados numa imagem fixa, as imagens oníricas ocupam um lugar descentrado da representação, a partir do qual os princípios de identidade e realidade deixam de exercer papel preponderante sobre $o$ ato de enunciação. As críticas de Breton ao racionalismo e aos escritores que priorizam o aspecto

\footnotetext{
${ }^{16}$ BENJAMIN, Walter. "Exposé de 1935," in Passagens.

17 "A intenção de Benjamin era desistir de toda interpretação manifesta e deixar o sentido aflorar tão somente pelo choque da montagem do material. A filosofia deveria não só subsumir o surrealismo, ela deveria tornar-se surrealista".ADORNO,T. "Caracterização de Walter Benjamin", in Prismas.
} 
descritivo da linguagem seguem, portanto, o mesmo espírito da crítica de Benjamin ao cientificismo ortodoxo nas ciências humanas.

As imagens oníricas aparecem entranhadas na realidade, segundo um plano externo à representação. O escritor tentará desentranhá-las comas palavras, colocando-as em relação recíproca com o desejo e a representação. Esta relação entre desejo e representação é o que confere às imagens dialéticas o estatuto de suprarrealidade. Escrita automática e justaposição de citações, beneficiando-se de certos recursos sintáticos inerentes à linguagem oral, associam as imagens oníricas de modo a aproximar realidades distantes, criando sentidos e enunciações paradoxais que manterão a coerência, ao mesmo tempo superior e desconhecida, do sujeito da representação. ${ }^{18}$ Essa coerência é característica crucial dos jogos de sincronia, tal como aparecem na noção de acaso objetivo em Breton e na noção de história em Benjamin, ambos sob o signo da "iluminação profana, de inspiração materialista e antropológica". ${ }^{19}$

Quem percebeu que as obras desse círculo não lidam com a literatura, e sim com outra coisa-manifestação, palavra, documento, bluff, falsificação, se se quiser, tudo menos literatura-, sabe também que são experiências que estão aqui em jogo, não teorias, e muito menos fantasmas. E essas experiências não se limitam de modo algum ao sonho, ao haxixe e ao ópio. $^{20}$

Benjamin notara, assim, que o principal achado surrealista não estava em suas formulações teóricas ou literárias, mas em sua busca por valorizar todas as dimensões da experiência humana. Ocorre que a associação de imagens com o intuito de aproximar realidades distantes segue uma via de pensamento pouco afim ao racionalismo científico e mais afeito ao pensamento esotérico. Alheio à representação e à sistematização da experiência, o pensamento esotérico concebe a multiplicidade sensível de acordo com uma noção de analogia que, ao prescindir de mediação reflexiva, coloca-a em relação imediata com a ideia do todo. Apesar do

\footnotetext{
${ }^{18}$ Breton cita Pierre Reverdy: "A imagem é uma criação pura do espírito". "Ela não pode nascer da comparação, mas da aproximação de duas realidades mais ou menos remotas". "Quanto mais longínquas e justas forem as afinidades de duas realidades próximas, tanto mais forte será a imagem-mais poder emotivo e realidade poética ela possuirá... etc".BRETON, A. Manifesto Surrealista de 1924

${ }^{19}$ BENJAMIN,W. "O Surrealismo, O Último Instantâneo da Inteligência Europeia", in Magia e Técnica, Arte e Política, p.23.

${ }^{20}$ BENJAMIN,W. "O Surrealismo, O Último Instantâneo da Inteligência Europeia", p.23.
} 
caráter contingente das associações, ele segue um critério cosmológico rigoroso, a partir do qual a analogia pode funcionar num único lampejo, sem mediação reflexiva, tornando plausível toda espécie de associação entre o micro e o macrocosmo. Filósofo e poetas e detêm nesta concepção esotérica da analogia, na expectativa de revelar um aspecto ainda não descoberto da realidade. Nas palavras de Breton: "o surrealismo repousa sobre a crença na realidade superior de certas formas de associações desprezadas antes dele, na onipotência do sonho, no desempenho desinteressado do pensamento". ${ }^{21}$

A possibilidade de liberar as imagens de sonho de sua paralisia vem acompanhada da possibilidade de um discurso que favoreça a descontinuidade e a heterogeneidade da experiência histórica. A sucessão temporal será interpretada à luz estática e descontínua do espaço, sendo a justaposição de fragmentos, recolhidos no passado e no presente, o procedimento alegórico de desvelamento do sentido histórico. A contemplação de seus pormenores materiais será um exercício de apreensão da verdade sobre a história. Assim, quanto maior a imersão do olhar nos estilhaços materiais da cultura, maior será a condição de visibilidade das imagens soterradas nas ruínas ideológicas.

${ }^{21}$ BRETON, André. Manifestos do Surrealismo, p.40. 


\section{BIBLIOGRAFIA}

ADORNO, Theodor. Caracterização de Walter Benjamin. In Prismas. SP: Ática, 2001.

BENJAMIN, Walter. Obras Escolhidas. Vol. I. Magia e Técnica, Arte e Política. SP: Brasiliense, 1985.

Obras Escolhidas. Vol. II. Rua de Mão Única. SP: Brasiliense, 1987. Origem do Drama Barroco Alemão. SP: Brasiliense, 1984.

Passagens. BH: UFMG, 2006.

BRETAS, Aléxia. Imagens do Pensamento em Walter Benjamin. InArtefilosofia.BH: Tessitura. № 6, 2009.

BRETON, André, Manifestos do Surrealismo, RJ: Nau, 2001.

BÜRGER, Peter. Teoria da Vanguarda. SP: CosacNaify, 2008.

FREITAS, Romero Alves. "Estilo e Método da Filosofia nos Primeiros Trabalhos de Walter Benjamin". In Mímesis e Expressão. BH: UFMG, 2001.

GAGNEBIN, Jeanne Marie. História e Narração em Walter Benjamin. SP: Perspectiva, 2009.

GATTI, Luciano. "Walter Benjamin e o Surrealismo: Escrita e Iluminação Profana". In Artefilosofia ํㅜ 6. BH: Tessitura, 2009.

LÖWY, Michael. Aviso de Incêndio. Uma Leitura das Teses Sobre o Conceito de História. SP: Boitempo, 2005.

MATOS, Olgária. "A Cena Primitiva, Capitalismo e Fetiche em Walter Benjamin". InvPensar a República.vBIGNOTTO, Newton org. BH: Humanitas, 2002.

KANGUSSU, Imaculada. "Suspensão e Imagens Dialéticas. Ou quando o Pensamento encontra o Sublime". In Mímesis e Expressão. BH: UFMG, 2001.

ROUANET, Sérgio Paulo. As Razões do lluminismo. SP: Companhia das Letras, 1987. 